\title{
Effects of local non-equilibrium in rapid eutectic solidification. Part 1: statement of the problem and general solution
}

\author{
Junfeng $\mathrm{Xu}^{1}$ and Peter Galenko ${ }^{2}$ \\ ${ }^{1}$ Friedrich Schiller Universität Jena Physikalisch-Astronomische Fakultät \\ ${ }^{2}$ Friedrich-Schiller-Universitat Jena
}

July 18, 2020

\begin{abstract}
Numerous experimental data on rapid solidification of eutectic systems exhibit the formation of metastable solid phases with the initial (nominal) chemical composition. This fact is explained by suppression of eutectic decomposition due to diffusionless (chemically partitionless) solidification beginning at a high but a finite growth velocity of crystals. A model considering the diffusionless growth is developed in the present work to analyze the atomic diffusion ahead of lamellar eutectic couples growing into supercooled liquid. A general solution of the model is presented from which two regimes are followed. The first presents diffusion-limited regime with the existence of eutectic decomposition if the solid-liquid interface velocity is smaller than characteristic diffusion speed in bulk liquid. The second shows suppression of eutectic decomposition under diffusionless transformation from liquid to one-phase solid if the solid-liquid interface velocity overcomes characteristic diffusion speed in bulk liquid.
\end{abstract}

\section{Hosted file}

Part 1 2020_07_07.docx available at https://authorea.com/users/343920/articles/470542effects-of-local-non-equilibrium-in-rapid-eutectic-solidification-part-1-statement-ofthe-problem-and-general-solution 


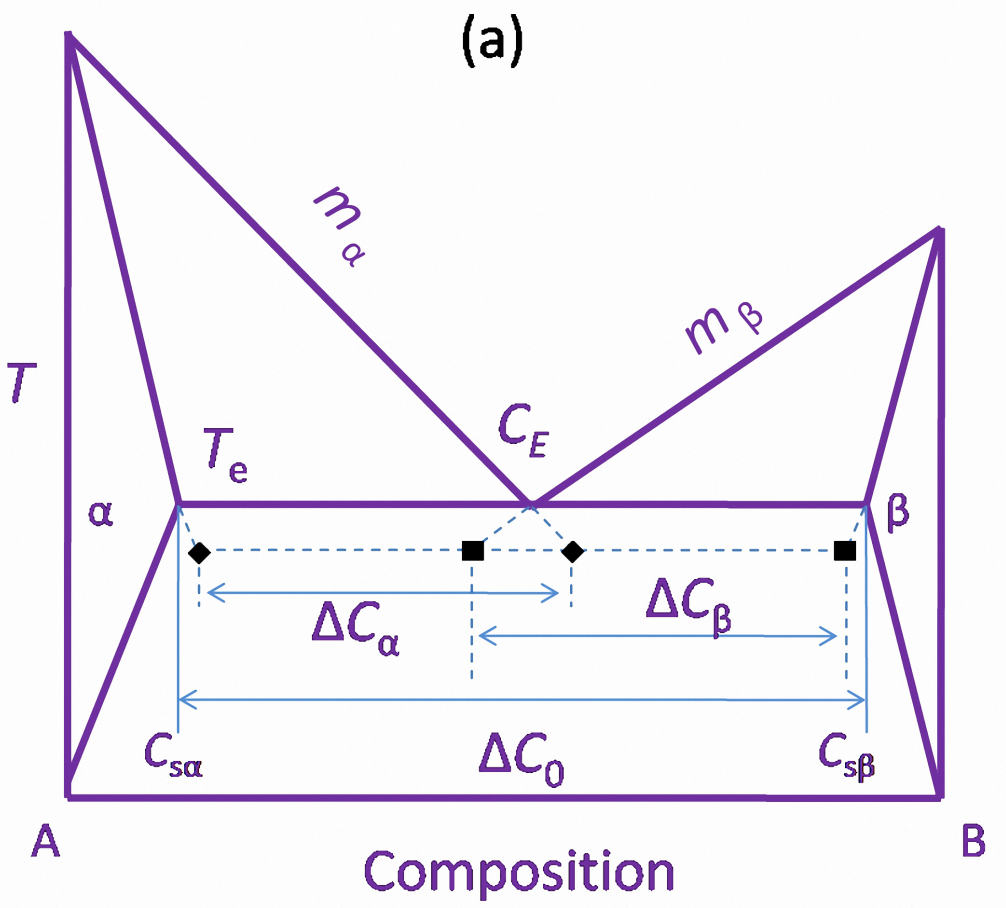



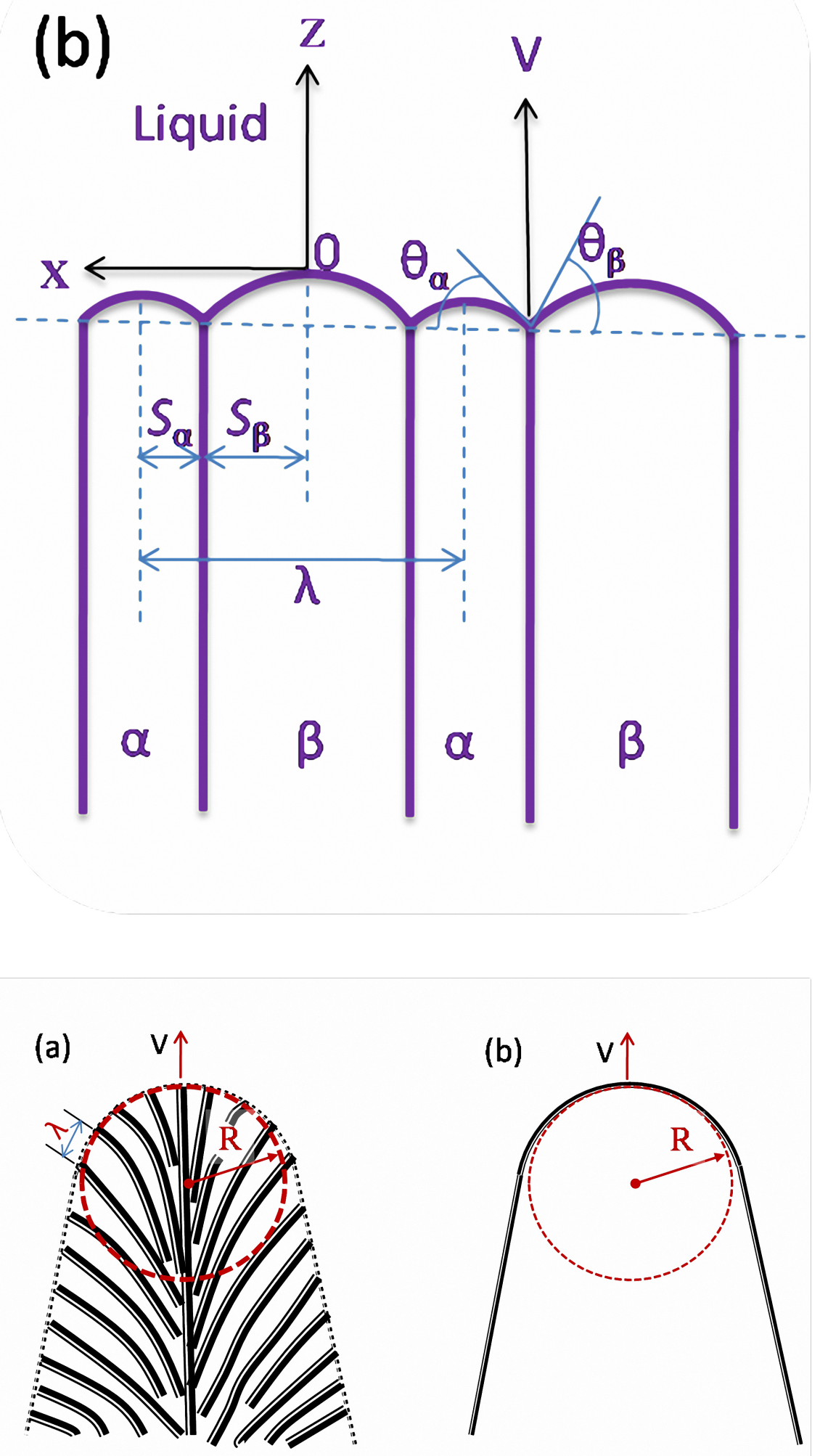